\title{
On effects produced by tidal power plants upon environmental conditions in adjacent sea areas
}

\author{
par A.V. Nekrasov, D.A. Romanenkov \\ Russian State Hydrometcorological Institute
}

\section{I INTRODUCTION}

Construction of a dam cutting off a past of marine basin, as well as the operation of the Tidal power plant (TPP), may result in a considerable transformation of paramelcrs, structure and energetic characteristics of adjacent tidal oscillations. Therefore the correct assessment of anticipated power capacity, scope of building works needed and possible environmental corsequences must be based not on the enaturat» data of sea level ranges existing before the start of the building but on the data predicted by numerical modieling taking into account expected transformation effects. These effects must be cxpecially significant when the planned TPP is of a scale great enough for the relevant geometric moditication of the basin to be comparable to a substantial portion of local tidal wave length. Some large-scale TPP concepts have becn advanced in Russia as poicntial prospects to be realized in future for the Bay of Mezen (White Sea) as well as for the Bay of Tugur and the Bay of Penzhina (Okhotsk Sea) [1, 2, $3,4]$. For the furst two designs the areats of tidel basirs detan ched by a barrage are enviseged to be about $2650 \mathrm{~km}^{2}$ and $1800 \mathrm{~km}^{2}$, whereas for the Bay of Penzhina two versions of the barrage position are proposed : the «northern» one with the tidal basin area of about $6800 \mathrm{~km}^{2}$, and the «southern» when practically all the Bay with arca of about $20000 \mathrm{~km}^{2}$ is supposed to be cut off. Whilst such designs are hardly realizable in the immediate future, the estimation of relevant possible effects on oceanographic conditions secms to be of some interest.

\section{ESSENTIALS OF TRANSFORMATION}

Some general and important transformation effects can be foreseen even before the moceling by considering the mechanism of transformation following from the long-wave nature of tidal phenomena. The most material of these effects caused by erection of a barrage can be principally studied using an elementary model of a gulf (fig. ha) having length $L$, constant width $b$ and depth $h$ and energy absorbing end at $x=O$ (simulating an energy dissipation in the head of the gu!f). Under natural conditions a progressive-standing wave motion exists in such a gulf as a result of partial reflection of a progressive tidal wave with amplitude $A$ entering the gulf from the left. The resulting amplitude $H$ and phase g distribution along the gutf can be chescribed 14] as:

$$
\begin{aligned}
& H=A\left(1+2 r \cos \beta+r^{3}\right)^{1 / 2} \\
& g^{3}=\operatorname{arctang}[\operatorname{tang} k x((l-r) /(l+r) /] ;
\end{aligned}
$$

where $\beta=2 k x$ and $r$ is a coeflicient of reflection at $x=0$ (wolid lines in $f i g .1 b$ ). If a barragc is created at $x=-l$, the following conseguences would lake place:

1) Refection point shiff. The site of reflection is moved for a distance $l$ from the gulf's head with the phase of reflected wave reduced by $2 k l$ ( $k=\sigma / \mathrm{N}^{\circ} h$ - is a wave number, $\sigma$ and $g$ being tidal frequency and gravity acceleration). It is seen from the Fig.lb (broken and dotted lines) that for $\hat{h}=\hat{\lambda}_{\mathrm{u}} / 2 \quad(\lambda=2 \pi / k$ - tidal wave length; this effect leads to increase in resulting tidal amplitude upstream of the barrage

Les changements entraines pä la construction et lexplotution d'une usine maréntotrice (rpp)dans les motvements des mareses (amplitudes, phases composition spectrale des oscillations du niveau de la mer positionnement des zones

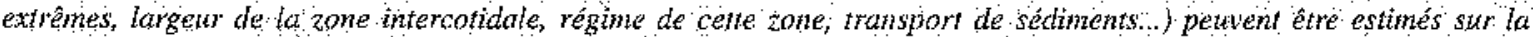
base đ'un modèle nathénatique. En gênéral, les effets sont proportionnels aux dinensions de la zone barrée par l'usine Les résultats présentés concenzent les projets de la mer Blanche et de la mer d'okhotsk. 


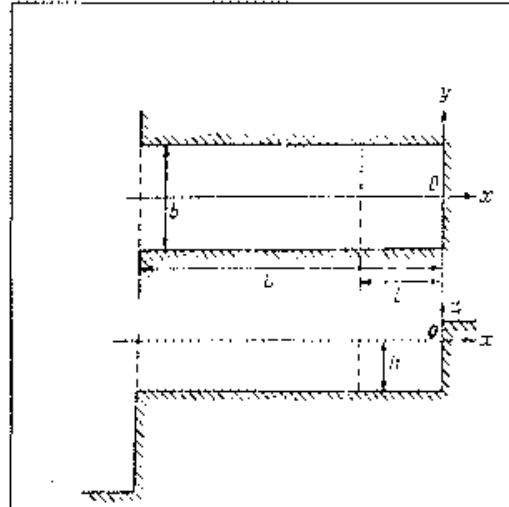

a)
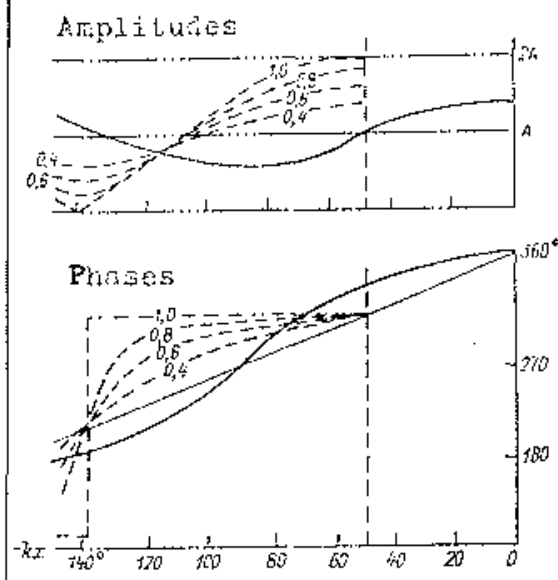

c)

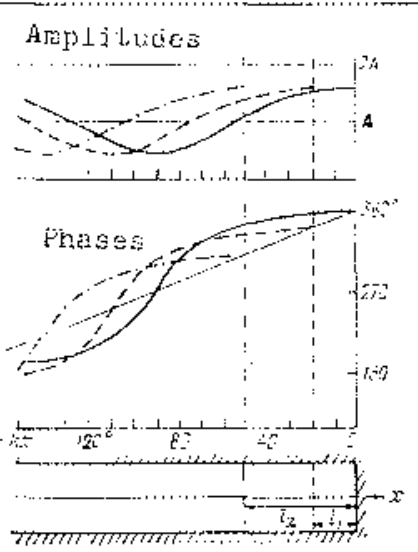

b)
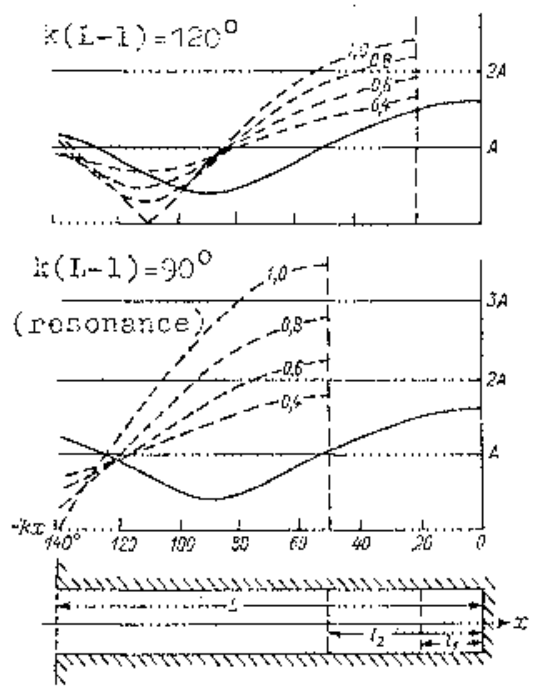

(1)
1. Transformation of tide by a TPP dam in an idealized basin

a) Sketch of a gulf with the I'P'P dam location

b) Transformation of tide caused by change in position of tidal wave reflection with fixed reflection coefficient $r=0.6$. Thin straight lines correspond to a progressive wave $(r=0)$

c) Transformation of tide caused by change in dissipation intensity. Reflection coefficients are given on cerves

d) Transformation of tidal amplitudes caused by change in resonance characteristics of a gulf.
2) Change in the basin dissipativity. As a nule the banage crection results in reduction of dissipalivity by two causes : (a) owing to interception of trually shallow and dissipative gulf's head and its climination from oscillatory process, and (b) owing to origination of an anlinodal zone adjacent to the barrage with correspondirig reduction of local tidal currents. Resulting oscillations approxinate to a standing wave with amplitudes increasing in front of the barrage (anti node) but decreasing (currents increasing) at a distance of $\lambda / 4$ from the barrage (node). In Fig.le the relevant transformation effects are shown for $k \lambda \div 50^{\circ}$ and dissipation corresponding. to incident wave energy losses cqual to $84 \%, 64 \%, 36 \%$ and zero (r equal to $0.4,0.6,0.8$ and 1 ).

3) Change in geometry and resonance fuming. This effect can be manifested if the open boundary (at $x-1-$ L) of the gulf is characterized by an appropriate internal reflection (sharp change in cross section, the shelf border) characterized by reflection coefficient $r_{3}$ (the power minus index means that it refers to a wave traveling in negative direction). The first reflection of the incident tidal wave occurs now not at $x+0$ but at $x=\cdot t$ and the length of the basin determining the wave travel time and resonance tuning becomes cqual not to $L$ but to $I, * l$. In a general way, the coefficient of retlection from the harrage $r_{b}$ also ditters from the 'natural' reflection coelficient $r$. As a result we obtain for transformed ampliture $H_{t}$ and phase $g^{\circ}{ }_{t}$ :

$\left.H_{s}=A\left(l I+2 r_{b} \cos 2 k(x+l)+r_{b}^{2}\right] / / J 2 q \cos 2 k(L-l)+q^{2} \|\right)^{1 / 2}$

$\left.\mathrm{g}^{0},=\operatorname{arctang}\left\{/\left(J \cdots r_{b}\right) \sin k x+2 k l\right] /\left(f+r_{b}\right) \cos k x+2 k l d\right\} ;$

where $q=r_{b}, r_{L}^{-}$. In Fig.ld the influence of geornetric $(I$. b) and dissipative $\left(r_{b}\right)$ factors is shown on the amplitude and phase transformation cffects (decrements) $\Delta H=H_{t}-H$ and $A g^{\circ}=g^{\circ}-g^{\circ}$ with given value of $r_{f}=0.4$. It is seen from this figure that, depending on initial geometry of the gulf, the erection of a barrage can bring the length $L_{i}=L-l$ of the remaining part of the basin closer both to resonance $I_{r e s}=(2 n+1) \lambda / 4$ or to anti-resonance $I_{{ }^{\prime}(n)}=(n+1) \lambda / 2$ values. The transformed lidal amplitude responds to that with either mianificalion or reduction. It is also seen that the greater this effect is manifested, the less are the energy losses duc to either dissipation or radiation from the gulf.

As some above mentioned concepts envisage creation of extremely large-scale tidal power plants with severed water areas of some thousands of square kilometers and expected 
powers of some tens of millions $\mathrm{kW}[1,2,3\}$, it preliminary assessment of transformation effects may be expedient as applied to great ocean-like adjacent water basins demanding to take the Coriolis force into account. It can be shown that in a wide basin of depth $h_{0}$ adjacent to a shetf of depth $h_{s}$ with energy absorbing coastal border, the tidal oscillation can be, as it rough approximation, structurally represented by a combination of two oppositely directed (incident and rellected) Kelvin waves. The resulting tidal chan pattern is deternined by the amplitude-phase relation belween these waves (module and argument of coefficient of complex reflection from the shelf edge) depending in tern on the depth relationship $h_{r} h_{r}$, the width of the shelf zone $L$ and the energy absorption (dissipation) intensity $d=1-r^{2}$ where $r$ is ayain the coefincient of reflection at $x=0$ (at the coustal borkter of the shelf zome). The two last parameters can be perceptitly modified if a great TPP is erected nearby the coast with a barage detaching the offshore part of the sheff.

In fig.2 the inthuente of variable barrage positions and energy losses on the tidal chat pattern is given for a tidal constituent $M_{2}\left(\sigma=1.405 .10^{-4} 5^{-5}\right)$ at the northern latitude $60^{\circ}$ in a basin of width $h=1200 \mathrm{~km}$ and $h_{n}=1000 \mathrm{~m}$ with $L=350 \mathrm{~km}, h_{\mathrm{s}}=62.5 \mathrm{~m}$. When allowing tor the Coriolis force, we restrict our attention to the area of the basin beyond the material manifestation of the Poincare standing waves which are concentrated in the vicinity of the shelf edge inside the zone of order of $\lambda_{0} / 4=\pi\left(g h h_{0}, j / 2 / 2 \sigma\right.$, what permits to represent the resulting tidal oscillations as a combination of two opposing Kolvin waves. In fig.2a the effect of impermeable (without losses) barrage erected at distances $l=0 ; 50 ; 75$ and $100 \mathrm{~km}$ from the coast is presented. By the asterisk the «yardstick» position of the amphidromic point is tenoted corresponding to the "naturad» case when the incident vidat wave loses $50 \%$ of its energy after rethection from the coast line (simulation of natural coastal dissipation with $d=0.5$ or $r=0.707$ ) in the absence of barsage. It is seen that the effect of an impermeabie barrage, tirstly, puts the amphidromic point on the central line of the basin and, secondly, shifts it from the shell for a distance far exceding $l$. The figs. $2 b-$ d itlustrate the effect of variable energy losses for relevant distances / showing that displacements of the amphidromic poinl from its "yardstick" position can reach hundreds and thousands kitometers. The pattern of co-tidal lines is especially sensitive to energy loss with $l=75 \mathrm{~km}$ corresponding to resonance situation for the remaining part of the shelf. In this case the suficiently great loss may cven result in reversal of sign of summary reflection from the shelf zone [4\} and interchanging positions of nodes and antiunodes.

In Fig. 3 the aralogous amplitude/phase patcm transformation is presented based on comparison of two numerical solutions the lirst of which corresponds to the eTaylor prob]ems [5] (supplemented with a bottom friction), and the second one - to a simitar problem differing from the first in that the gulf has an entergy absorbing (or outward-radiating) portion of the reflecting bordcr positioned at the right (with respect to incoming Kelvin wave) of it [6F. The geometry of the basin $(L=400 \mathrm{~km}, b=275 \mathrm{~km}, h=100 \mathrm{~m})$ is in a rough agreement with the Gulf of Shetikhov adjacent to the Bay of Penzhina the latter dissipating a great part of incoming tidal wave energy by admitting its energy-laden right wing. According to configuration of this geographical region and existing assessments of dissipation, the value $d=0.8$ was specified for the right one third of the reflecting border. As a

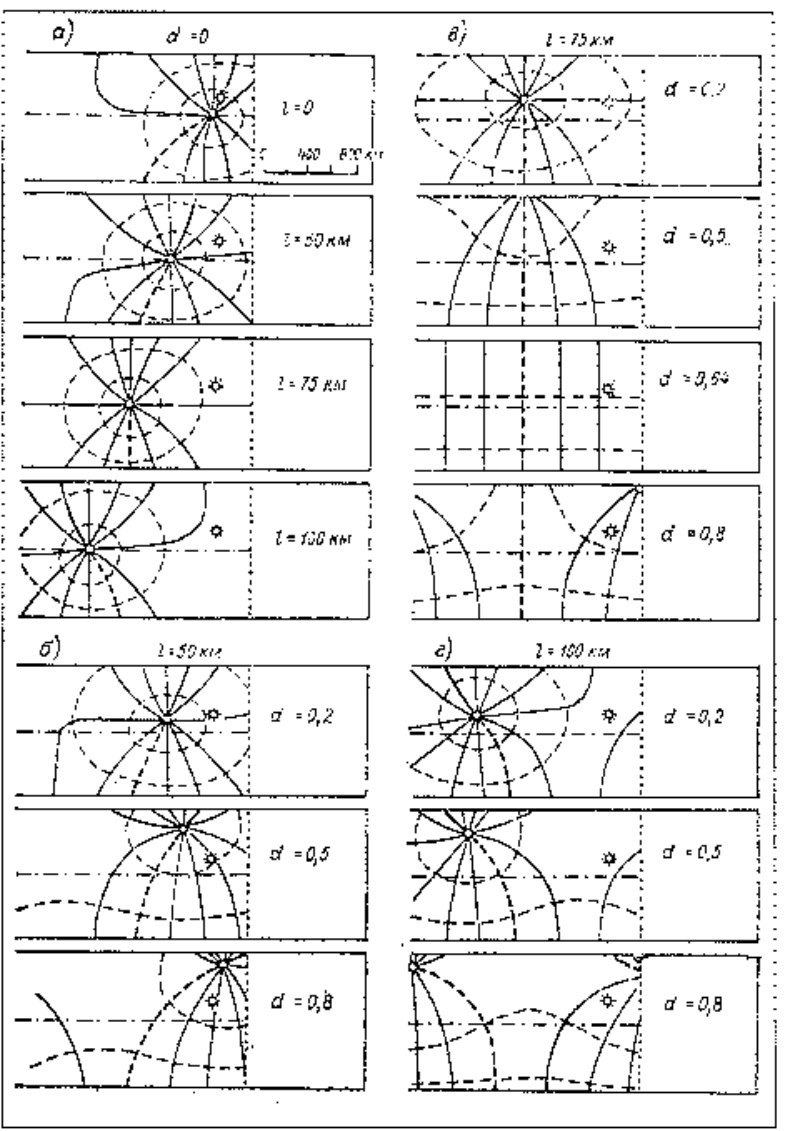

2. Influence of barrage position (1) and absorption intensity (d) upon tidal chart pattern in adjacent ocean-like basin, High-waters and low-waters for $t=0$ are designated with heavy and dotted co-tidal lines. Position of the «natural» amphidromic point (with $\mathrm{l}=0, \mathrm{~d}=0.5$ ) is indicated with an asterisk.

testle an amphidromic system is formed in the lower left part of the basin. The closing of the appendix-absorber by a impermeable batrier (specifying $d=0$ for all parts of the coast of the gulf) symmetriyes the pieture of tidal chart putting the amphidromic point on the central tine. In bottom iragments of fig ? the characteristic features of transformation the shows demonstrating the amplitude amplification reduction coefficients $\triangle H / H$ and phase positive and negative decrements $\Delta g^{\circ}$ extremely pronounced in the vicinity of the nodal zone and resembling in combination a clubs tigurc with $\Delta H / H$ and $\Delta g^{\circ}$ opposite areals arranged in pairs lengthwise and crosswise of the nodal lint. It is also seen that the negative $\Delta H$ area, disposed on the right side, is significantly less in size than the positive one.

\section{Uᄑ PREDICTIVE MODELENG}

The implementation of mathematical modcling for prediction of expected transformation of tidal characteristics was started about twenty years ago. By now, a fairly great numiber of predictive tidal models are developed and realized $[7$, $8,9,10$ et al.j. Some estimates of transformation related to large-scale TPP concepts proposed for the Bay of Mczen, the Bay of Tugur and the Bay of Penzhina are presented below. The relevant areas are shown in figs 4 and 5 . 
3. Characteristic pattern of amplitude and phase transformation in a rectangular gulf simulating the Gulf of Shelikhov as responded to cessation of energy absorption on a part of the boundary.

a) and b) Tide with and without energy absorption

c) Transformation of amplitudes $(\Delta \mathbf{H} / \mathbf{H})$

d) Transformation of phases $\left(\Delta \mathrm{g}^{a}\right)$.

Tidal energy horizontal tlux is also given.

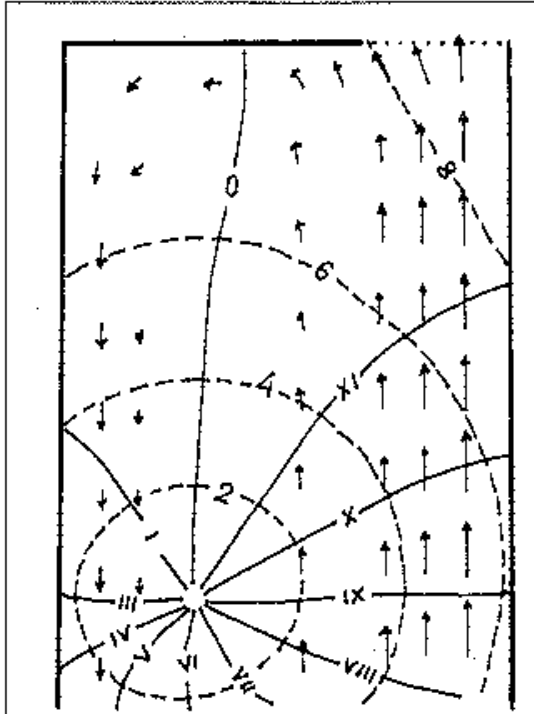

a)

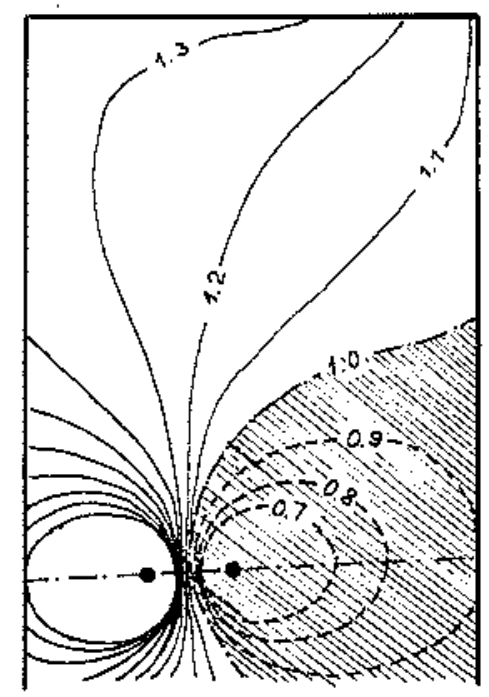

c)

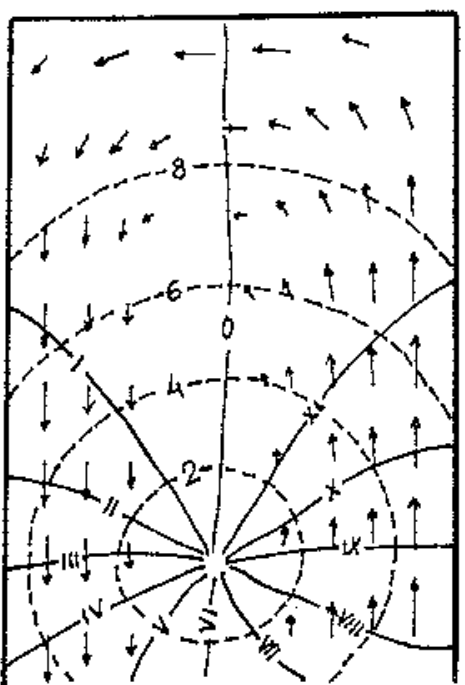

b)

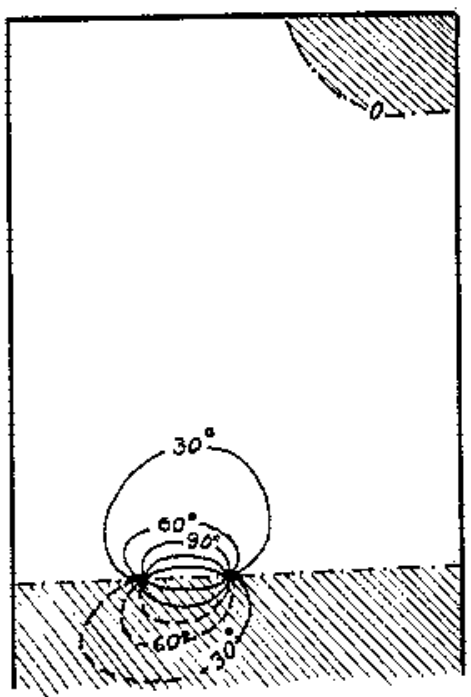

d)

\subsection{Bay of Mezen}

The tides in the Bay of Mexen maly heve the range reaching $10 \mathrm{~m}$ and are of nearly pure semi-diumal type what makes it possible to restriet the consideration only with the $M_{2}$ constituent detcrmining the primcipal features of summary tidal oscillations in this region. The modeling was performed basing on D. Greenberg's method:8] with the use of the rominear vertically avcraged hydrodynamic shallow water equations which ate to be integrated numerically on a staggered finite-difference grid [9]. The boundary conditions of different types have been employed corresponding :

(i) to the coastline (including in turn the atixed nom-permeable boundary" and "moving boundary», allowing for the flooting and drying of inter-tidal zone, versions) ;

(ii) to the open or «liquid" boundary where cither specified values of tidal oscillations (sea surface displacements $\zeta$ or current components $u, v$ ) or so-called «impedance» condition (prescribing not $\zeta$ or $u, v$, but a certain relationship between (hem) are to be set; and

(iii) to the TPP harrage with specification of the discharge regime through the generating units and sluices or with the non-permeability condition is calse of a blind dam. The model area covering the Bay of Xczen with the Voronka region and incorporating the position of the barrage with the site of the tidal station on it is shown in fig. 4 .

In lig.6 the transformation of amplitudes and phases of the $M$, tidal constituen (predominating in this region) caused by a blind dam and a barrage with a discinarge regime specified for one-side «ebb operation» is presented. It follows from this assessment that the crection of a dam would result in rise of tidal amplitudes in the most part of the area considered with the increase greater in the castern part. The transformation of phases is also greatest in the castern part exceeding there one hour and with distinct separation into zones of positive and negative increments. The modified pattcm of tidal oscillations detemines the changes in inter widal zone shown in fig.th. The detachment of the head of the Bay of Mezen excludes a considerable portion of this zone about $435 \mathrm{~km}^{2}$ of the total area $715 \mathrm{~km}^{2}$ - from the areat exposed to tidal oscillations (the situation inside the tidal basin, where the changes have very specific character, is not considered here). At the same thme contain increase in the 


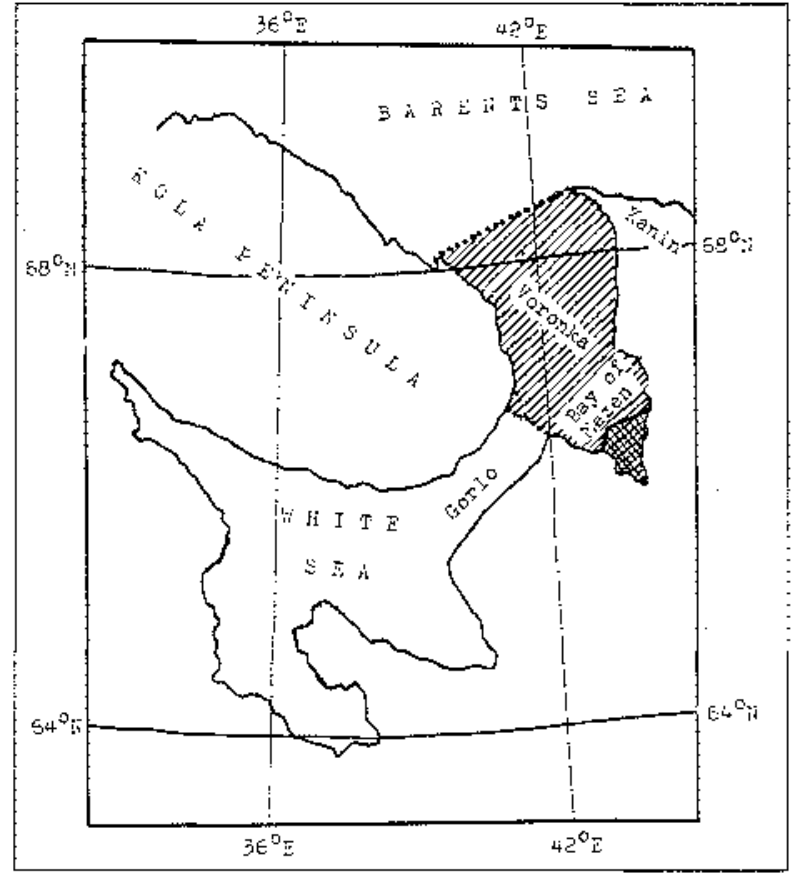

4. Mezen TPP modeling area in the White Sea.

Slant hatching - modeling area,

Cross"hatching - detached tidal basin.

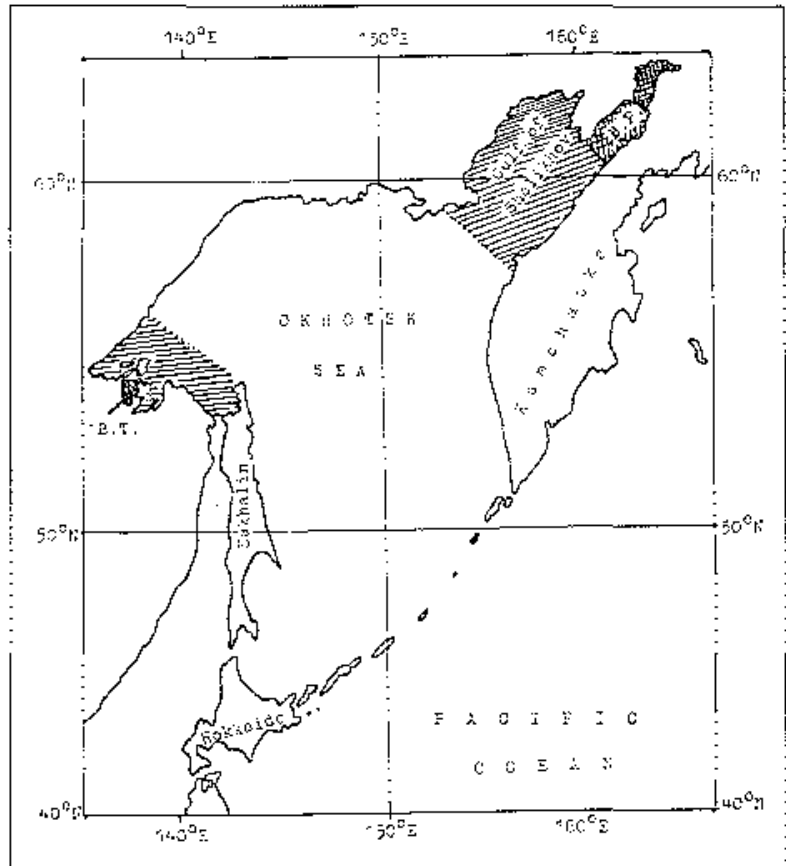

5. Modeling areas in the Okhotsk Sea

BT - Bay of Tugur,

BP - Bay of Penzhina.

Slant hatching - modeling area,

Cross-hatching - detached tidal basin.

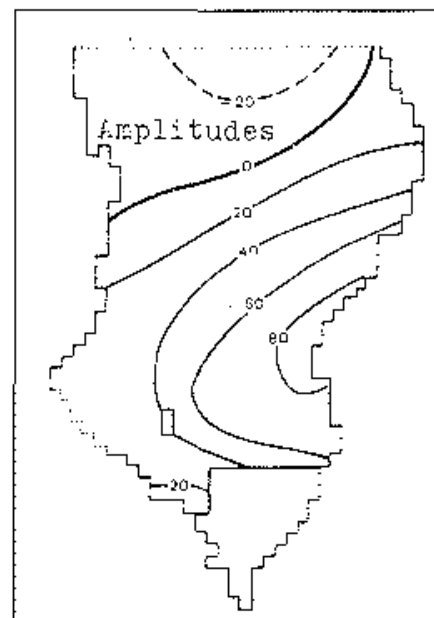

a)
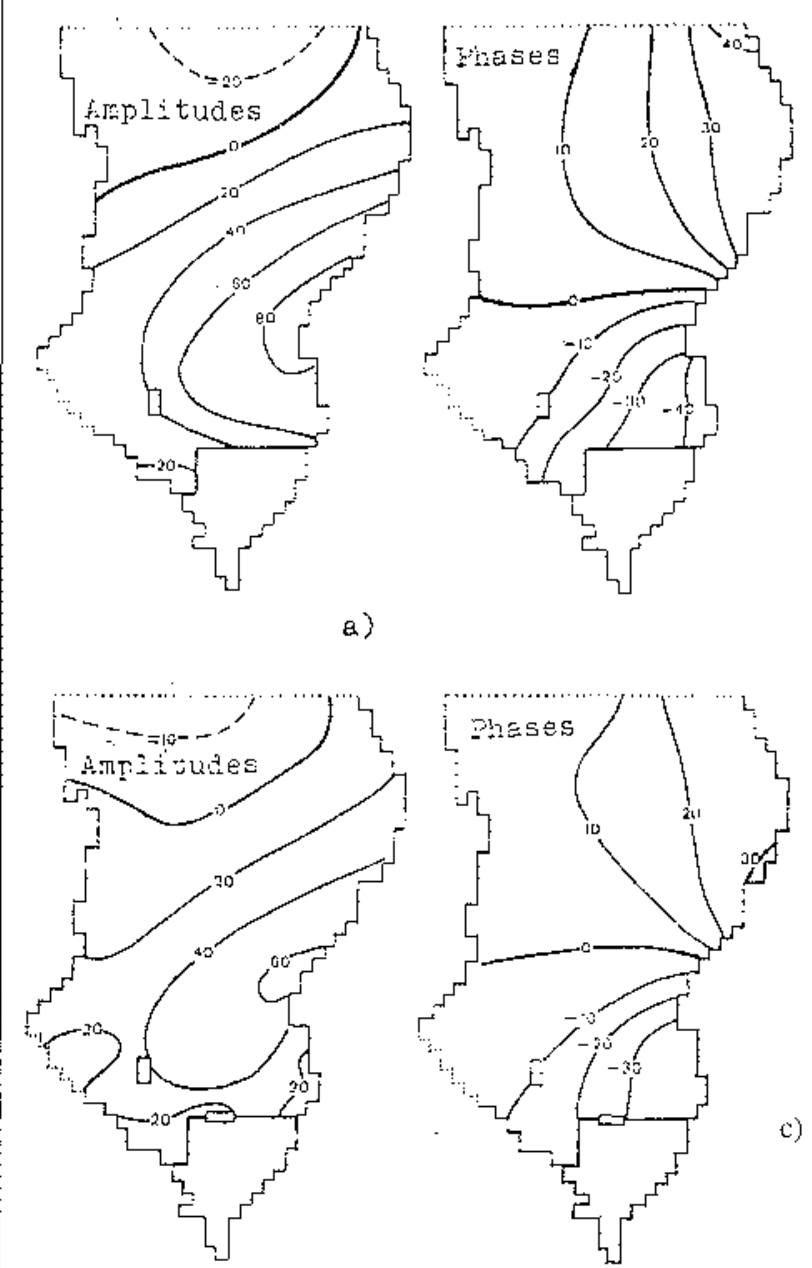

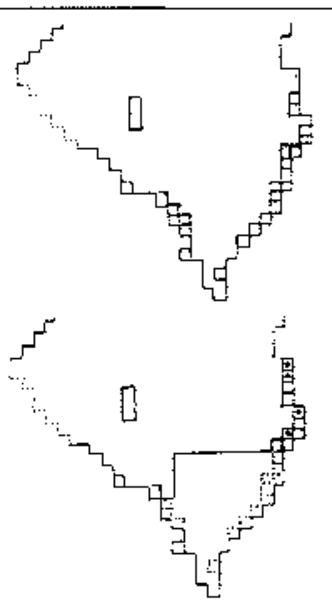

b)
6. Transformation of $\mathrm{M}_{2}$-tide in the Bay of Mezen caused by the TPP.

a) Transformation by a dam of amplitudes fdifferences in $\mathrm{cm}$ ) and phases (differences in deg.),

b) Changes in position of inter tidal zone caused by a dam.

$\square$ a mesh of inter-tidal zone under natural conditions

.. mesh excluded from flooding/drying process

$\mp$ new inter-tidal mesh.

c) Transformation by a barrage with TPP in operation. 


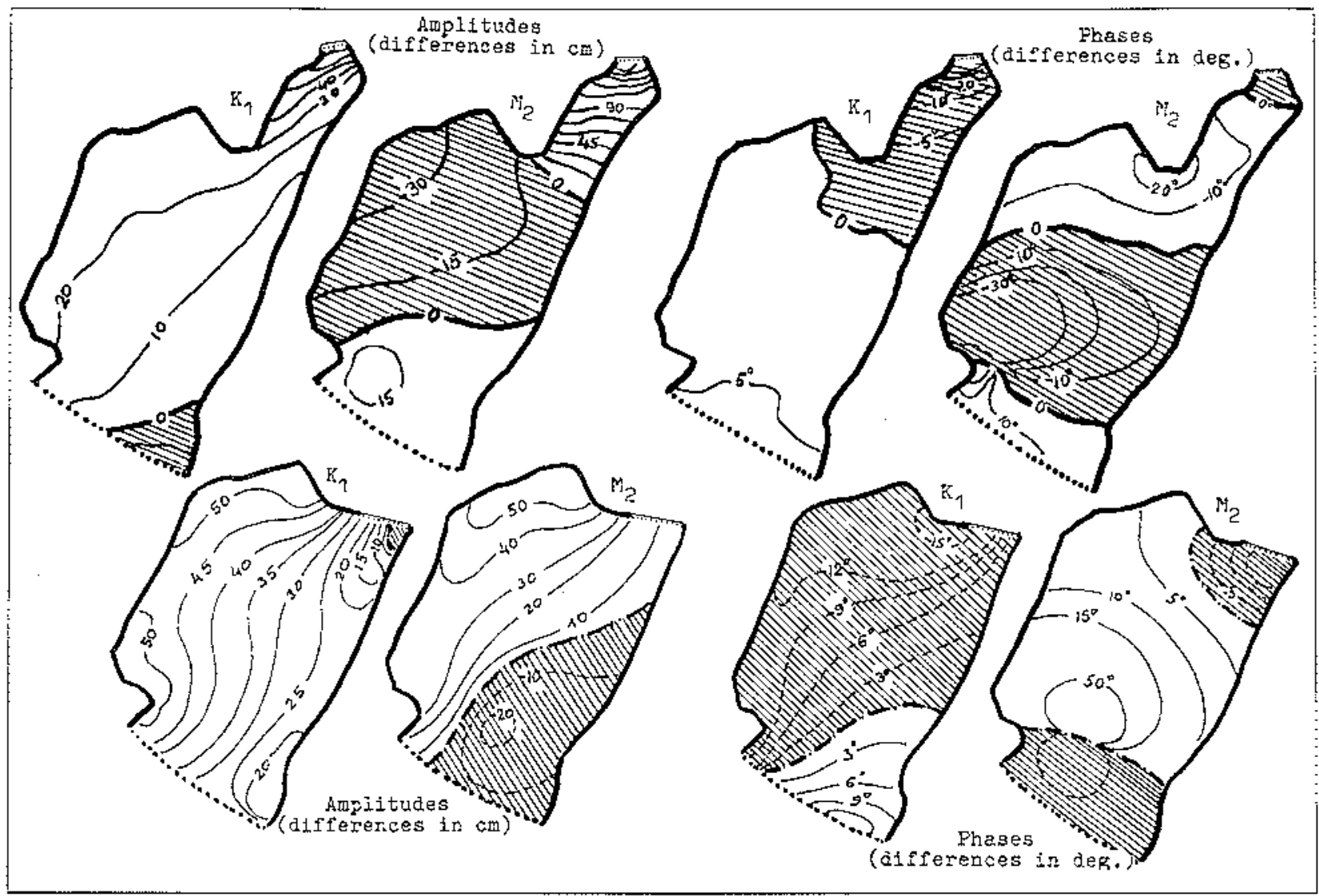

7. Transformation of tidal constituents in the Gulf of Shelikhov.

Top - effect of the northern dam,

Bottom - effect of the southern dam.

inter-tidal zone area of about $124 \mathrm{~km}^{2}$ takes place mainly in the region of amplitudes amplitication near the eastern crast. Effects produced by a barrage with operating units and sluices are generally similar to those caused by a blind dam but all the changes atc manifested a little slower. Additional disturbances produced in oscillations by the TPP action are of secondary imporance being restricted within the immediate neighbouthood of the barrage. It is a gencral rule remaining valid for all the numerical experiments fulfulct in relation with the TPPs under consideration.

\subsection{Bay of Tugur}

Though the tidal osciltations in the Bay of Tugur (their range reaches $9 \mathrm{~m}$ ) also belong to the semi-riumal type, the role of diumal components is not negligible and the modeling must incluobe the combination of a number of principal constituents. Actualty, 10 principal constituents have been taken into account when modeling. For this basin the method of curvilinear coordinates have been employed permitting to improve the approximation of natural boundarics by coordinate lines and to get higher resolution for regions of special interest. The main subject of matter was the transformation of the sumnary tide by a dam erected (in accord with the existing concept) in the narrowest part of the Bay bearing in mind that the dimensions of the Bay of Tugur are much smaller than the local length of tidal wave.

As would be expected. the modeling showed that the damming brings to arising of the anti-node area in front of the barage with an increase of the amplitudes and decrease of tidal currents. The local phase decrease also takes place meaning that high and low waters would occur some eartic! due to the dam. The special attention has been paid to effects touching on residual tidal currents and tidal mixing. It is apparent that the residual currents were considerably reduced with their maximum velocity dropping from 13 to $2 \mathrm{~cm} / \mathrm{s}$ close to the dam. As for the tidal mixing, the calculation of Simpson-Hunter criterion $\log _{t o}(h / /)$ ) [11] intimated that the reduction of tidal cuments from $2.4 \mathrm{~m} / \mathrm{s}$ to 15 $20 \mathrm{~cm} / \mathrm{s}$ in the vicinity of the dam would restlt in locel decay of tidal mixing and so the formation of a density stratificd area becones quite probable (fig. 8 ).

\subsection{Bay of Penzhina}

In the tidal oscillations in the Bay of Penzhina (BP) and adjacen Gulf of Shelikhov (GS) the diumal components dominate over semi-diurnal ones and the type of local summary tide is generally qualified as diurnal with maximum range reaching about $13 \mathrm{~m}$. Attempts to assess the consequences of supposed TPP creation in the BP have bect undertaken repeatedly with the modeling based on D. Greerrberg's method in the 70 -ies and 80 -ies $[12,13,14]$. Recently sonc new results were obtained by using the curvilinear coordinates technique [6] applied to the unitcd $B P+G S$ region as well as to the entirc Okhotsk Sea what perrnitted to study the transformation elfects and to trace the range of their action over vast areas beyond the nearest proximity of 


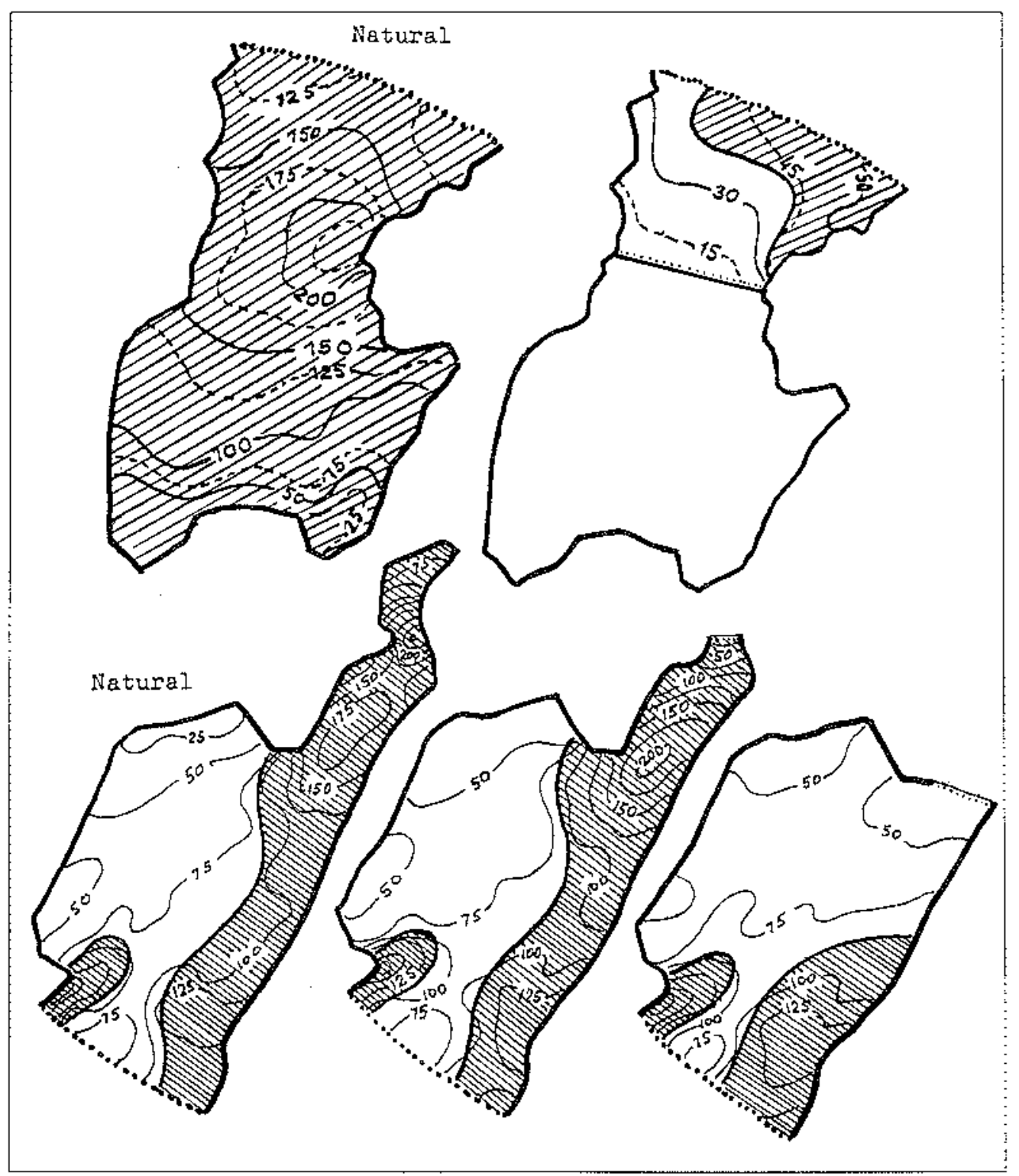

8. Transformation of tidal mixing

Maximum tidal stream velocities (in $\mathrm{cm} / \mathrm{s}$ ) are given (with isolines) as well as supposed mixed (hatched) and stratilied (white) zones.

Top - Tugur Bay, Bottem - Gulf of Shelikov and Penzhina Bay.

the TPP dam. The numerical experiments were fulfilled both for summary tide and for separate tidal constituents to facilitate the physical interpretation of results. In this relation, the $M_{2}$ and $K$, constivents are civeussed below.

The consideration of the amplitude/phase modification (fig.7) makes obvious the great role of the Cortols force in the mechanism of local tidal regine formation. The character of effects in cuse of southen version of the dam is strueturatly quite similar to titat fisplayed in the fig.3 which represents the principal features of transtormation caused by the closure of an energy sink placed on the «right hend» side (as regards the incident Kelvin wave) of the retlecting bottcond boundary of a gull. Like in righ-angle basin considered above, the positive charge (increase) is aranged to the leth hand side of the outside tidat basin exceeding $0.5 \mathrm{~m}$ for both the tidal constituents. The distinctive feature of the $M_{2}$ constituent is the negative change area occming on the right-hand side of the GS with extreme values at a distance of about a quarter of local tidal wave length from the dam, i.c. in the nodal zone. As the diurnal tidat wave is twice longer than the semi-diumal one, the similar nodal line for the $K_{i}$ constituent has to be situated much father from the dam and so the «negative» zone for $K_{i}$ is displaced far long to the south-eastern part of the Okhotsk Sea (tig. 10) adjacent to the Kurl Istand chain with its size and distance from the dam much targer comparing to $M_{3}$ because not only of difference due to periods, but also through larger depth and local $\lambda$ value. In casc of northen position of the dann the seni-diusnat tidat component seems to be more responsive than the diurnal one, what can be explained by the resonance effect similar to that shown in fig.ld. This effect, resuleing in considerable amplitication of $M_{2}$ amplicudes within the resling part of the Bay of Penzhina, provides also the total decay of the semi-diurnat wave rehection from the $\mathrm{BP}$ due to the phenomenon similar to "clearance" occurring on application of an antireflection coating in optics.

In fig.8 some effects connected with transformation of tidal mixing are shown. Position of mixed and stratificd arcas, as well as the frontal zones separating them, car be materially changed duc to transformation of tidal currents fickd. Tinis result refers to tide combining ten constituents of differen periods.

Different response of tidal constituents to dam construction brings to tratsformation of spectral structure of oscilla- 


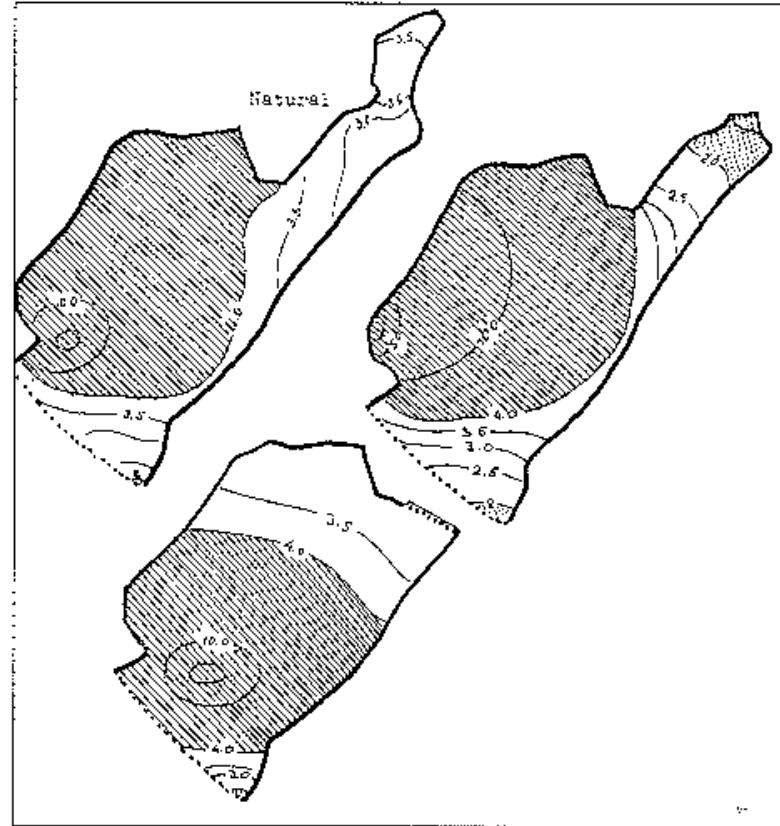

9. Transformation of tidal types (spectral structure) in the Gutf of Shetikhov and Penzlina Bay caused by northerm and southern dams. Isolines of tidal type criterion

$\mathbf{D}=\left(\mathrm{H}_{\mathrm{K}, 3}+\mathrm{H}_{\mathrm{Ol}}\right) / \mathrm{H}_{\mathrm{s} 22}$ are given,

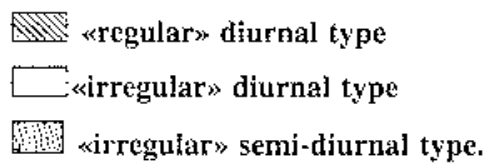

tions manifested in modification of the "type of tide" expressed as parametcr $D)=\left(H_{K}+H_{O}\right) / H_{M}$. In fig. 9 it is seen that the retevan modiftcation also may be of sensible amount especially in connection with resonance effects in case of northern tocation of the dam. Elfects of this sor may be of particutar importance for coastal areas affceting 10 iffe regime of orginisms inhabiting inter-tidal zonc.

The most of ransformation effects considered here correspond to general rules treatcd above what facilitates the interpretation of results obtained by the numerical modeding.

\section{References}

[1] Birksil:me L. B. (196:). - Tidial Power Plants in Mociorn Power Eagigeeting. Gosetergoizdal, 271 g. fin Rtussitarj.

[2] Borksittis L.B. (1979). - Designing of Lidal plants it the LSSR. Proc. of the 13: Symp. of the Colston Res. Soc. , p.67-75.

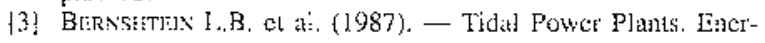
gortomiriata, 296 p. (in Ressian).

[4. Nikrasov A.Y. (1990). - Encroy of Ocean Tides. Gidroneteoizdal, 288 p. (in Russian).

(5) TAY:OR G.J. \{1921). - Tidtat osctllations it: gulds and rectabgula: basins. Proc. London Matr. Soc. Vol.20, No 2, p.148181.

[6] Ronantakov D.A. (1996). - Predictive modeling of tides ir. the Okhotsk Sea. Abstr. of the Theses Doct. Googr. St. Peletsbigg. 16 p. (in Rissicin).

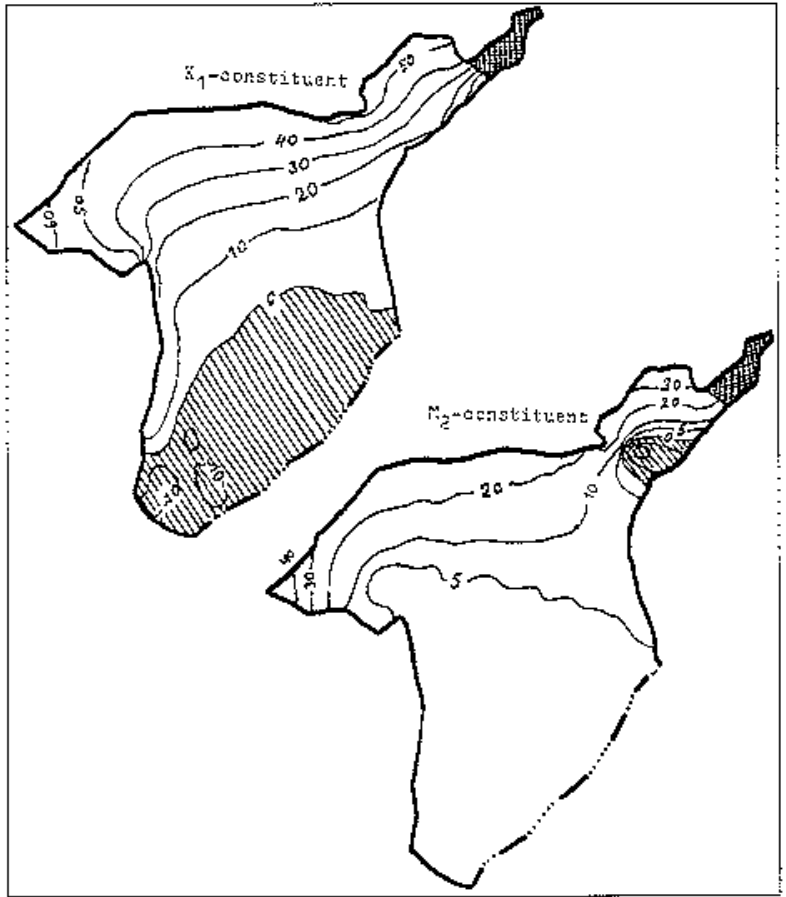

10. Transformation of tidal constituents in the Okhotsk Sea. Differences (in $\mathrm{cm}$ ) of amplitudes catsed by the southern dam in the Penzhina Bay are given.

$\square$ positive differences,
negative differences,
鼠 detached tidat basin.

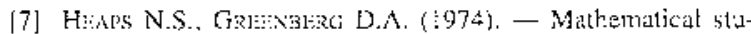

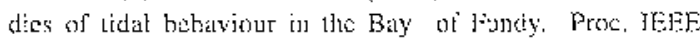

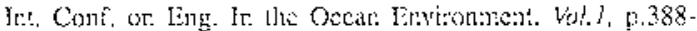
399.

181 GREmasere D.A. (1979). - A nutrerical mode: investigation of tidal phenomena in the Buy of Fuady attit Glit: of Mane. Marinc Gcodesy. 1/2:2, No 2, 2.16:-187.

[9] Gorlit.xoy V.M. Nikknscy A.V. (1982), -- Mode:irg of somi-dittrna: Lice in a shallow busin taking in toceotne the booring and dying of a conkial fone. Tratestactions of the Leningtat Hydrometconologicit] Institu: No. N7, p.140-146. fin Rissianj.

10: BARuvov O.G.: Golkil.kov V.M. (1983). - Trans[omalion of didrual tidal regime $\left(K_{1}-\right.$ constituent) ir tise Bay of Pe:r bina, Okkotsk Sca, due 10 construetion of ticat power plant. Methods of matsformatom of ocean enersy, ,65-71. (in Ruts siant.

[1]] SlMasox J.H. (j981). - Shelf sea fronts, irplications of uncir existence and bet:aviour. Philos. Trans. R. Soc.Loním, Ser. A 302, p. $531-546$.

1:2| Barwov O.G., Gorki.kov V.M. (1984). - Changes bi) encegy characteristics of tidat movements in the Bay of Penzhina die to hydiolechrical constal engincering. Employment of ocean tidal and wind weries energy p. 60-66. in Russianj.

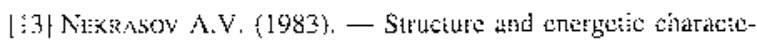
risties of tide in the Bay of Penzhtua and thei: transformation due to ercelion of a TPP dam. Methods of tramsfomation of orean energy p.56-64. (in Russian;

[14) N[?KRASCN A.V. (1984). - Mtalysis of transfomation of lictal oscilations in tine bay of Penzbina caused by a construction of TPP dam. Employment of ocean sidest and und wares energyi p.52-60. (in Rissians. 